\title{
Türk Turizm Sektöründe Finansman Kararlarının Alt Sektörler Kapsamında Karşılaştırmalı Analizi
}

\section{Comparative Analysis of Financial Decisions in Turkish Tourism Sector in the Context of Sub-Sectors}

\author{
Doç. Dr. Erdinç KARADENIZ \\ Mersin Üniversitesi \\ Turizm Fakültesi \\ E-posta:ekaradeniz@mersin.edu.tr \\ Orcid Id:0000-0003-2658-8490
}

\author{
Arş. Gör. Mehmet BEYAZGÜL \\ Mersin Üniversitesi \\ Turizm Fakültesi \\ E-posta:mehmetbeyazgul@mersin.edu.tr \\ Orcid Id:0000-0002-3139-4351
}

\author{
Arş. Gör. Selda DALAK \\ Mersin Üniversitesi \\ Turizm Fakültesi \\ E-posta: seldakhl@mersin.edu.tr \\ Orcid Id:0000-0003-2735-1006 \\ Arş. Gör. Fatih GÜNAY \\ Mersin Üniversitesi \\ Turizm Fakültesi \\ E-posta: fgunay@mersin.edu.tr \\ Orcid Id:0000-0003-0892-514X
}

\section{Öz}

Bu çalışmanın temel amacı Türk turizm sektörünü oluşturan Konaklama, Yiyecek ve İçecek Hizmeti Faaliyetleri, Seyahat Acentesi ve Tur Operatörlüğü Faaliyetleri ve Spor Faaliyetleri, Eğlence ve Dinlence Faaliyetleri alt sektörlerinin finansman kararlarının karşılaştırmalı olarak analiz edilmesidir. Bu kapsamda, Türkiye Cumhuriyet Merkez Bankası (TCMB) sektör bilançolarından faydalanılarak alt sektörlerin 2012, 2013 ve 2014 yıllarına ait finansal tabloları kullanılarak her bir sektör için 12 finansal yapı oranı hesaplanmıştır. Yapılan analiz sonucunda turizm alt sektörlerinin yabancı kaynak ile finansmanı tercih etmeleri sebebiyle finansal risklerinin yüksek olduğu saptanmıştır. Vade yapısı bakımından incelendiğinde alt sektörlerin kısa vadeli yabancı kaynakları daha çok tercih ettikleri belirlenmiştir. Seyahat Acentesi ve Tur Operatörlüğü Faaliyetleri dışındaki sektörlerde varlık yapılarının duran varlık ağırlıklı olduğu dolayısıyla turizm alt sektörlerinde varlık ve kaynak kompozisyonuna dikkat edilmediği saptanmıştır.

Anahtar Kelimeler: Turizm alt sektörleri, Türkiye Cumhuriyet Merkez Bankası, oran analizi, sektör bilançoları, finansal yapı.

\begin{abstract}
The aim of this study is to comparative analyze of financial decisions of Accommodation Activities, Food and Beverage Service Activities, Travel Agency and Tour Operator Activities, Sports Activities and Amusement and Recreation Activities subsectors in the Turkish tourism sector. In this context, by using Central Bank of the Republic of Turkey Company Accounts calculated 12 financial structure ratios for each subsector between 2012-2014 years. In the results of analysis, it is determined that tourism subsector use mainly liabilities and debt so it is raise financial risks. In respect to maturity of liabilities it is determined that tourism subsectors prefer short term debt. Except Travel Agency and Tour Operator Activities subsectors, other subsectors mainly have fixed assets so it is determined that they have maturity mismatching between their assets and debts.
\end{abstract}

Keywords: Tourism subsectors, Central Bank of Republic of Turkey, ratio analysis, company accounts, financial structure. 


\section{Giriş}

Turizm sektörü kendi içinde birbirine bağlı çok sayıda alt sektörü içeren büyük bir yapıdan oluşmaktadır. Bu bağlamda alt sektörlerin farklı yapılarda ve kendilerine has özellikler taşımaları turizm sektörünün daha kırılgan ve karmaşık bir hal almasına neden olmaktadır. Turizm işletmeleri, değişken talep düzeyi, ekonomik ve siyasi bağlamda yüksek risk ve belirsizlik ortamının yanı sıra sabit sermaye yatırımlarının genel olarak yüksek, bununla birlikte operasyonel maliyetlerin kontrolünün de günden güne zorlaştığı, düşük kar marjı ve yüksek döviz kuru riskinin olduğu bir sektörde faaliyet göstermektedir. Söz konusu sebeplerden dolayı turizm işletmeleri, varlık ve kaynak yapılarını dengeleyememelerinin yanı sıra sistematik ve sistematik olmayan risk unsurlarından etkilenmeleri sebebiyle kısa ve uzun dönemde vadesi gelen borçlarının anapara ve faizinin ödenmesi konusunda finansal sıkıntılarla hatta iflas riskiyle karşı karşıya kalabilmektedirler. Son yıllarda birçok büyük turizm işletmesinin bu açıdan finansal sıkıntıya girdiği veya iflas ve iflas erteleme başvurusunda bulunduğu görülmektedir. Bu duruma örnek verilmek istenirse dünyanın sayılı golf otelleri arasında sayılan Lykia World Antalya ve Lykia World Fethiye'nin sahibi Silkar Turizm'in yaşadığı süreç gösterilebilir. Yüklü bir borçla mahkemeye giden Silkar'ın yalnızca özel bir bankaya 237 milyon lira borcu bulunmaktadır. Lykia Group için yapılan başvuru, turizm sektöründe son dönemlerde yapılan en büyük iflas erteleme isteği olarak kayıtlara geçmiş durumdadır. Lykia Group için yapılan iflas erteleme başvurusunda finansal sıkıntıya girmenin nedenleri olarak hızı büyüme, döviz kurlarındaki düşüş, Euro bölgesinde yaşanan sorunlar, kredi faiz oranlarındaki yükseliş ve oda fiyatlarındaki düşüş gösterilmiştir (Gökçe, 2015).

$\mathrm{Bu}$ bağlamda turizm sektöründe faaliyet gösteren işletmelerin başarılı olabilmelerinin yolu, uygun varlık ve finansman yapılarını belirleyerek yatırımlarını gerçekleştirmeleri, sağlıklı bir nakit akışı sağlamaları, sermaye maliyetlerini düşürmeleri ve firma değerini maksimize etmelerinden geçmektedir. Turizm işletmelerinin finansman yapılarını oluşturabilmeleri için öncelikle varlık yapılarına uygun olarak finansal kaynak bileşimini dengelemeleri gerekmektedir. Dolayısıyla finansman yapısı firma değerini doğrudan etkileyen bir unsur olarak karşımıza çıkmaktadır. Firma değerini doğrudan etkilemesi sebebiyle finansman yapısı, turizm işletmeleri açısından yüksek önem arz etmektedir. Bu nedenle turizm sektörünün finansman yapısı incelenmek istendiğinde, bu sektörü oluşturan her bir alt sektörün finansman yapılarının nasıl şekillendiğinin ve birbirlerinden hangi yönleri ile ayrıştığının incelenmesi gerekmektedir.

Bu bağlamda çalışmanın amacı, Türkiye Cumhuriyet Merkez Bankası Sektör Bilançoları (TCMB) üzerinde Konaklama, Yiyecek ve İçecek Hizmeti Faaliyetleri, Seyahat Acentesi ve Tur Operatörlüğü Faaliyetleri ve Spor Faaliyetleri, Eğlence ve Dinlence Faaliyetleri alt sektörlerinin 2012, 2013 ve 2014 yıllarındaki finansman yapılarının incelenerek aradaki farklılıkların ortaya konması şeklinde belirlenmiştir. Analiz sürecinde konaklama, yiyecek ve içecek hizmeti faaliyetleri, seyahat acentesi ve tur operatörlüğü faaliyetleri ve spor faaliyetleri, eğlence ve dinlence faaliyetleri alt sektörlerinin finansal durum tabloları kullanılarak oran analizi tekniği ile finansal yapıları karşılaştırmalı olarak ortaya konmaya çalışıımıştır. Belirlenen amaçlar doğrultusunda çalışma dört bölümden oluşmaktadır. Birinci bölümde konuyla ilgili daha önce gerçekleştirilmiş çalışmalar literatür başlığı altında verilmektedir. İkinci bölümde çalışmanın veri ve yöntemi hakkında bilgiler sunulmaktadır. Üçüncü bölümde araştırmanın bulguları sunulmaktadır. Sonuç bölümünde ise genel bir değerlendirme yapılarak öneriler sunulmaya çalışılmıştır. 


\section{Literatür Taraması}

Konuyla ilgili literatür incelendiğinde turizm sektörü ve turizm sektörü dışındaki işletmelere yönelik genel olarak finansal yapı veya sermaye yapısı tercihleri ile finansal performans arasındaki ilişkiyi farklı zaman dilimleri içerisinde inceleyen çalışmaların gerçekleştirildiği görülmektedir.

Turizm sektörü dışındaki sektörlere yönelik olarak gerçekleştirilen çalışmalar incelendiğinde farklı sektörlerde finansman tercihlerinin nedenleri veya finansman tercihlerinin belirleyicileri üzerine araştırmalarında gerçekleştirildiği belirlenmiştir. Arslan (2005), İstanbul Menkul Kıymetler Borsası'nda işlem görmekte olan Türk reel sektör firmalarının sermaye yapısını analiz ettiği çalışmasında, firmaların uzun vadeli borç kullanmaktan kaçındığını ve kısa vadeli borcu tercih ettiklerini saptamıştır. Küçüközmen ve Oğuz (2008), Konya'da 73 küçük ve orta büyüklükteki işletmenin ağırlıklı olarak özkaynak yoluyla finansmanı tercih ettiklerini saptamışlardır. Değirmen ve Gündoğdu (2010), İstanbul Menkul Kıymetler Borsası'nda işlem gören 86 ihracat işletmesinin 1997-2008 yıllarında finansman kaynağı olarak öncelikle kısa vadeli banka kredilerini, daha sonra uzun vadeli banka kredilerini ve son olarak hisse senedi ihraç etmeyi tercih ettiklerini belirlemişlerdir. Gençtürk, Dalğar ve Yılmaz (2011), İstanbul Menkul Kıymetler Borsası'nda 1992-2009 yılları arasında işlem gören şirketlerin finansman tercihlerinin kriz dönemlerinde farklılaştığını ve bu şirketlerin ağırlıklı olarak uzun vadeli yabancı kaynak kullanmayı tercih ettiklerini saptamıştır. Sayılgan ve Uysal (2011), çalışmalarında 1996-2008 yılları arasındaki TCMB ana sektörlerin bilançoları üzerinde panel veri analiz tekniğini kullanarak sermaye yapısını etkileyen değişkenleri ortaya koymuşlardır. Çalışma sonucunda işletmelerin, sermaye yapılarını etkileyen değişkenleri, dengeleme teorisi kapsamında belirledikleri saptanmıştır. Antzoulatos, Apergis ve Tsoumas (2011), finansal yapının, sektörlerin performansı üzerinde uzun vadede etkili olduğunu belirlemişlerdir. Salameh, Al-Zubi ve Al-Zubi (2012), gelişmekte olan ülkelerde aktif karlıı̆̆ı ile kaldıraç arasında negatif bir ilişkinin olduğunu belirlemişlerdir. Rioja ve Valev (2012), 1976-2000 yıllarına ait finansal verilerine ulaşılabilen 62 ülkenin ekonomik büyüme ve finansal yapıları arasında ilişki olduğunu saptamışlardır. Swain ve Patnaik (2013), Hindistan'daki şirketlerin performanslarının bire bir finansal yapıyla ilişkili olduğunu belirlemişlerdir.

Konuyla ilgili turizm sektörüne yönelik literatür incelendiğinde ise turizm şirketlerinin finansman tercihleri ve bu tercihleri etkileyen unsurlar incelenmekle beraber finansman veya sermaye yapısı kararlarının finansal performansa olan etkilerinin araştırıldığı görülmektedir. Kim ve Ayoun (2005), çalışmalarında 1997-2001 yılları arasında turizm sektörünü oluşturan konaklama, havayolu, eğlence ve restoran alt sektörlerinin oran analizi yöntemiyle finansal performansları karşılaştırmalı olarak incelemişlerdir. Çalışma sonucunda analizde yer verilen oranlar bağlamında konaklama, havayolu, eğlence ve restoran alt sektörlerinin finansal performanslarının farklı olduğu belirlenmiştir. Küçükaltan ve Eskin (2008), turizm şirketlerinin 2006-2007 yıllarında kalkınma bankası kredilerinden yararlanma düzeyinin düşük olduğu, otel işletmelerinin uzun vadeli finansman kullanımında bankalardan yararlandıklarını belirlemişlerdir. Bichon (2009), Avrupa'da faaliyet gösteren otellerin kredi taleplerini incelediği çalışmasında, performans, imaj ve varlık yapılarına dikkat edildiğini belirlemiştir. Küçükaltan ve Açıkgöz (2011), IMKB'de işlem gören turizm şirketlerinin 2005-2009 yılları arasında ağırlıklı olarak yabancı kaynak kullanımına yöneldiklerini ve özkaynak seviyelerini belirli bir noktada tuttuklarını saptamışlardır. Karadeniz ve arkadaşları (2012), Türkiye Cumhuriyet Merkez Bankası'nın yayımladığı oteller ve lokantalar sektör bilançoları üzerinde gerçekleştirdikleri çalışmada 1990 ve 2009 yılları arasında sektörün kaynak yapısında daha çok uzun vadeli yabancı yabancı kaynak 
kullanılı̆̆ı ve varlıkların finansmanında devamlı sermayeye ağırlık verildiğini saptamışlardır. Civan ve Cenger (2013), halka açık turizm şirketlerinde 2009-2012 yıllarında finansman yapısı ve karlılık arasında direkt bir ilişkinin olmadığını belirlemişlerdir. Fritsch ve Ivy (2014), finansal piyasalardaki yatırımcıların ve sigorta şirketlerinin, otellere finansör olma konusunda daha istekli olduklarını fakat daha yüksek getiri beklediklerini belirlemişlerdir. Serrasqueiro ve Nunes (2014), Portekiz'deki KOBİ statüsündeki otellerin finansman sürecinde öncelikle içsel fonları, daha sonra yabancı kaynakları ve son olarak öz kaynakları tercih ettiklerini saptamışlardır. Kahiloğulları ve Karadeniz (2015), hisseleri Avrupa ve Türkiye borsalarında işlem gören konaklama şirketlerinin finansman yapılarını oran analizi yöntemiyle incelemişlerdir. Çalışmanın sonucunda Türkiye'deki halka açık konaklama şirketlerinin ağırıklı olarak öz kaynak ile finansmanı, buna karşın Avrupa'daki halka açık konaklama şirketlerinin yabancı kaynak ile finansmanı tercih ettikleri ve finansal kaldıraçtan daha fazla faydalandıkları saptanmıştır.

\section{Araştırmanın Yöntemi}

Bu çalışmanın amacı; TCMB sektör bilançoları üzerinde konaklama, yiyecek ve içecek hizmeti faaliyetleri, seyahat acentesi ve tur operatörlüğü faaliyetleri ve spor faaliyetleri, eğlence ve dinlence faaliyetleri alt sektörlerinin 2012, 2013 ve 2014 yıllarındaki varlık ve kaynak yapılarının incelenerek finansman tercihlerinin oran analizi yöntemiyle karşılaştırmalı olarak ortaya konulmasıdır. Bu kapsamda turizm sektörünü oluşturan alt sektörlerin belirlenmesinde TCMB'de yer aldığı haliyle ve Avrupa Topluluğunda Ekonomik Faaliyetlerin İstatistikî Sınıflaması (NACE) dikkate alınmıştır. Bu kapsamda yapılan sınıflandırmada alt sektörler; konaklama, yiyecek ve içecek hizmeti faaliyetleri, seyahat acentesi ve tur operatörlüğü faaliyetleri ve spor faaliyetleri, eğlence ve dinlence faaliyetleri olmak üzere 4 başlık altında toplanmıştır. Çalışmanın amaçları doğrultusunda bilgi edinme yasası kapsamında konaklama, yiyecek ve içecek hizmeti faaliyetleri, seyahat acentesi ve tur operatörlüğü faaliyetleri ayrıca spor faaliyetleri, eğlence ve dinlence faaliyetleri alt sektörlerinin 2012, 2013 ve 2014 yıllarına ait sektör bilançoları elektronik ortamda TCMB'den istenmiştir. İşletmelerin gönüllülük esasına bağlı olarak finansal tablolarını paylaşması ile söz konusu alt sektörlerin finansal tablolarının düzenlenmesinde en geniş bilgiye sahip olması nedeniyle TCMB'ye başvurulmuştur. Bu bağlamda konaklama sektöründe 421, yiyecek ve içecek hizmeti faaliyetleri sektöründe 72 , seyahat acentesi ve tur operatörlüğü faaliyetleri sektöründe 52 , son olarak spor faaliyetleri, eğlence ve dinlence faaliyetleri sektöründe 17 işletmenin finansal durum tablolarının ayrı ayrı konsolide edilmesinden oluşturulan sektör bilançoları kullanılmıştır.

Finansal yapı analizinde işletmelerin kaynak yapısı hakkında daha geniş bilgi sağladığı düşünülen oran analizinden faydalanılmıştır. Finansal tablolarda yer alan iki kalem arasındaki ilişkinin matematiksel olarak ifadesine oran veya rasyo denilmektedir (Langemeier, 2004; Ceylan ve Korkmaz, 2008). Çalışmanın amaçları doğrultusunda kaynak yapısının analizinde finansal yapı oranları kullanılmıştır. Analizde kullanılan finansal yapı oranları, bu oranların hesaplanma yöntemleri ve ne ifade ettikleri Tablo 1 yardımıyla açıklanmıştır.

Analizde konaklama alt sektörü, yiyecek ve içecek hizmeti faaliyetleri alt sektörü, seyahat acentesi ve tur operatörlüğü faaliyetleri alt sektörü, spor faaliyetleri, eğlence ve dinlence faaliyetleri alt sektörlerinin her biri ve her yıl için 12 adet oran hesaplanmıştır. Çalışmada dört alt sektör bağlamında ve 2012, 2013 ve 2014 yılı için toplamda 144 gözlem gerçekleştirilmiştir. 
Tablo 1: Finansal Yapı Oranları

\begin{tabular}{|c|c|c|}
\hline Finansal Yapı Oranları & Hesaplanış Şekli & Kullanılış Amacı \\
\hline Kaldıraç Oranı & $\begin{array}{ll}\text { Yabancı } & \text { Kaynak/Varlık } \\
\text { Toplamı }\end{array}$ & $\begin{array}{l}\text { İşletmenin varlıklarının ne kadarını yabancı } \\
\text { kaynaklarla finanse edildiğini ölçmek. }\end{array}$ \\
\hline $\begin{array}{l}\text { Öz Kaynakların Toplam } \\
\text { Kaynaklara Oranı }\end{array}$ & $\begin{array}{l}\text { Öz kaynak/ Toplam } \\
\text { kaynak }\end{array}$ & $\begin{array}{l}\text { Iş̧letmenin varlıklarının ne kadarının öz sermaye ile } \\
\text { finanse ettiğini ölçmek. }\end{array}$ \\
\hline $\begin{array}{lr}\text { Toplam } & \text { Yabancı } \\
\text { Kaynakların } & \text { Öz } \\
\text { Kaynaklara Oranı } & \end{array}$ & $\begin{array}{l}\text { Toplam Yabancı } \\
\text { Kaynak/Öz kaynak }\end{array}$ & $\begin{array}{l}\text { İşletmenin borçları ile öz kaynak arasındaki ilişkiyi } \\
\text { ölçerek firmanın finansal riskini belirlemek. }\end{array}$ \\
\hline \begin{tabular}{ll} 
Kısa Vadeli & Yabancı \\
Kaynakların & Kaynak \\
\multicolumn{2}{c}{ Toplamına Oranı }
\end{tabular} & KVYK/Toplam Kaynak & $\begin{array}{l}\text { İşletmenin kaynak toplamı içerisinde kısa vadeli } \\
\text { borçlarının ağırlığını ölçmek. }\end{array}$ \\
\hline \begin{tabular}{ll} 
Uzun Vadeli & Yabancı \\
Kaynakların & Kaynak \\
\multicolumn{2}{l}{ Toplamına Oranı }
\end{tabular} & UVYK/Toplam Kaynak & $\begin{array}{l}\text { İşletmenin aktiflerinin ne kadarlık kısmının uzun } \\
\text { vadeli borçlarla finanse edildiğini ölçmek. }\end{array}$ \\
\hline $\begin{array}{lcr}\text { Ticari } & \text { Borçların Kısa } \\
\text { Vadeli } & \text { Yabancı } \\
\text { Kaynaklara Oranı }\end{array}$ & Ticari Borç /KVYK & $\begin{array}{l}\text { İşletmenin kısa vadeli borçlarının ne kadarlık bir } \\
\text { kısmının ticari borç olduğunu ölçmek. }\end{array}$ \\
\hline $\begin{array}{l}\text { Finansal Borçların Uzun } \\
\text { Vadeli } \quad \text { Yabancı } \\
\text { Kaynaklara Oranı }\end{array}$ & Finansal Borç/UVYK & $\begin{array}{l}\text { İşletmenin uzun vadeli yabancı kaynakları } \\
\text { içerisinde finansal borç oranını ölçmek. }\end{array}$ \\
\hline $\begin{array}{l}\text { Finansal Kiralamanın } \\
\text { Uzun Vadeli Yabancı } \\
\text { Kaynaklara Oranı }\end{array}$ & Finansal Kiralama/UVYK & $\begin{array}{l}\text { Işsletmenin uzun vadeli yabancı kaynaklarının ne } \\
\text { kadarlık bir bölümünün finansal kiralama borcu } \\
\text { olduğunu ölçmek. }\end{array}$ \\
\hline $\begin{array}{lr}\text { Uzun Vadeli } & \text { Yabancı } \\
\text { Kaynakların } & \text { Toplam } \\
\text { Yabancı } & \text { Kaynaklara } \\
\text { Oranı } & \end{array}$ & UVYK/Yabancı Kaynak & $\begin{array}{l}\text { Yabancı kaynakların ne kadarlık bir bölümünün } \\
\text { uzun vadeli borçtan oluştuğunu ölçmek. }\end{array}$ \\
\hline $\begin{array}{lr}\text { Kısa Vadeli } & \text { Yabancı } \\
\text { Kaynakların } & \text { Toplam } \\
\text { Yabancı } & \text { Kaynaklara } \\
\text { Oranı } & \\
\end{array}$ & KVYK/Yabancı Kaynak & $\begin{array}{l}\text { Yabancı kaynakların ne kadarlık bir bölümünün } \\
\text { kısa vadeli borçtan oluştuğunu ölçmek. }\end{array}$ \\
\hline $\begin{array}{lr}\text { Banka } & \text { Kredileri/Kısa } \\
\text { Vadeli } & \text { Yabancı } \\
\text { Kaynaklar } & \\
\end{array}$ & Banka Kredileri/KVYK & $\begin{array}{l}\text { Kısa vadeli yabancı kaynaklar içerisinde banka } \\
\text { kredilerinin oranını göstermektedir. }\end{array}$ \\
\hline $\begin{array}{lr}\text { Banka } & \text { Kredileri/Uzun } \\
\text { Vadeli } & \text { Yabancı } \\
\text { Kaynaklar } & \end{array}$ & Banka Kredileri/UVYK & $\begin{array}{l}\text { Uzun vadeli yabancı kaynaklar içerisinde banka } \\
\text { kredilerinin oranını göstermektedir. }\end{array}$ \\
\hline
\end{tabular}

Kaynak: (Andrew ve Schmidgall; 1993, Brealy ve diğ.; 1995, White, Sondhive Fried; 1997, Jagels ve Coltman; 2004, Önal, Karadeniz ve Koşan , 2006, Ceylan ve Korkmaz; 2008).

\section{Bulgular}

Çalışmanın amaçları doğrultusunda gerçekleştirilen analizler sonucunda alt sektörler bağlamında elde edilen farklılıkların daha iyi görülmesi amacıyla her bir orana ait ortalamalar alt sektöre göre karşılaştırmalı olarak tablolarda verilmiştir. Yapılacak karşılaştırmalar ve sektörün aktif yapısına yapılacak atıflarda fayda sağlaması bağlamında öncelikle turizm alt sektörlerinin dönen ve duran varlıkların toplam aktif içerisindeki payları yüzde cinsinden sunulmaktadır.

Türk turizm sektörünü oluşturan alt sektörlerin aktif yapısı incelendiğinde konaklama ve spor faaliyetleri, eğlence ve dinlence faaliyetleri alt sektörlerinin ortalama \%25 dönen varlık, \%75 duran varlık yani sabit sermaye ağırlıklı işletmelerden oluştuğu görülmektedir. Yiyecek ve içecek hizmeti faaliyetleri alt sektörünün (Y\&i) tamamının aktif yapısı incelendiğinde ortalama duran ve dönen varlık oranlarının birbirine yakın seyrettiği görülmektedir. Dolayısıyla Y\&l sektörünün, \%56 duran varlık ve \%43 dönen varlıklardan oluştuğu ve söz konusu sektörün aktif yapısının nerdeyse eşit ağırlıkta 
olduğu dikkat çeken bir unsurdur. Seyahat acentesi ve tur operatörlüğü faaliyetleri sektörünün aktif yapısı bağlamında diğer üç sektörden tamamen ayrıştığı analiz sonuçlarında dikkat çeken bir diğer noktadır. Seyahat acentesi ve tur operatörlüğü faaliyetleri sektörünün ortalama $\% 22$ duran varlık ve $\% 78$ dönen varlık ağırlıklı işletmelerden oluştuğu saptanmıştır.

Tablo 2: Turizm Alt Sektörlerinin Aktif Yapısı

\begin{tabular}{|c|c|c|c|c|}
\hline & & $\begin{array}{l}\text { Dönen } \\
\text { Varlık \% }\end{array}$ & $\begin{array}{l}\text { Duran } \\
\text { Varlık \% }\end{array}$ & $\begin{array}{l}\text { Aktif } \\
\text { Toplamı \% }\end{array}$ \\
\hline \multirow{4}{*}{ 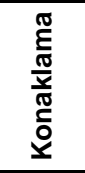 } & 2012 & 24,40 & 75,60 & 100 \\
\hline & 2013 & 26,90 & 73,10 & 100 \\
\hline & 2014 & 26,50 & 73,50 & 100 \\
\hline & Ort. & 25,93 & 74,07 & 100 \\
\hline \multirow{4}{*}{$\bar{\varnothing}$} & 2012 & 47,80 & 52,20 & 100 \\
\hline & 2013 & 41,70 & 58,30 & 100 \\
\hline & 2014 & 42,40 & 57,60 & 100 \\
\hline & Ort. & 43,97 & 56,03 & 100 \\
\hline \multirow{4}{*}{ 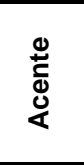 } & 2012 & 77,40 & 22,60 & 100 \\
\hline & 2013 & 78,30 & 21,70 & 100 \\
\hline & 2014 & 77,60 & 22,40 & 100 \\
\hline & Ort. & 77,77 & 22,23 & 100 \\
\hline \multirow{4}{*}{ ㅎํㅇ } & 2012 & 21,90 & 78,10 & 100 \\
\hline & 2013 & 26,40 & 73,60 & 100 \\
\hline & 2014 & 26,70 & 73,30 & 100 \\
\hline & Ort. & 25,00 & 75,00 & 100 \\
\hline
\end{tabular}

Karadeniz ve arkadaşları (2012), oteller ve lokantalar sektörünün finansman kararlarını inceledikleri çalışmalarında sektörün sabit sermaye ağırlıklı olduğunu saptamışlardır. Bu bağlamda turizm sektörünün seyahat acentesi ve tur operatörlüğü faaliyetleri alt sektörü dışında sabit sermaye ağırlıklı işletmelerden oluştuğu yargısı kısmen desteklenmiş sayılmaktadır.

Tablo 3'te ise analize dahil alt sektörlerin kaldıraç oranları karşılaştırmalı olarak sunulmaktadır.

Tablo 3: Turizm Alt Sektörlerinin Kaldıraç Oranları

\begin{tabular}{|l|c|c|c|c|}
\hline Yabancı Kaynak/Toplam Kaynak Oranı & $\mathbf{2 0 1 2}$ & $\mathbf{2 0 1 3}$ & $\mathbf{2 0 1 4}$ & Ort. \\
\hline Konaklama & 0,59 & 0,67 & 0,69 & 0,65 \\
\hline Yiyecek ve İçecek Hizmeti Faaliyetleri & 0,60 & 0,70 & 0,74 & 0,68 \\
\hline Seyahat Acentesi ve Tur Operatörlüğü Faaliyetleri & 0,82 & 0,85 & 0,86 & 0,84 \\
\hline Spor Faaliyetleri, Eğlence ve Dinlence Faaliyetleri & 0,65 & 0,70 & 0,75 & 0,70 \\
\hline
\end{tabular}

Yabancı kaynakların toplam kaynaklar içindeki payını gösteren kaldıraç oranına bakıldığında turizm alt sektörlerinde faaliyet gösteren işletmelerin ağırlıklı olarak yabancı kaynak ile finansmanı tercih ettikleri gözlenmektedir. Bu durum, kaldıraç etkisinden yararlanmaları bağlamında olumlu bir sonuç olarak görülse de finansal riski artırıcı bir unsur olması bağlamında dikkat edilmesi gereken bir husustur. Yabancı kaynaklar içerisinde kısa vadede ticari borçların, uzun vadede banka kredilerinin tek finansman kaynağı olmaları yabancı kaynak yaratmak konusundaki sıkıntıları bir kez daha ortaya çıkarmaktadır. Kim ve Ayoun (2005), turizm sektörlerinin farklı oranlarını 
hesapladıkları çalışmalarında konaklama ve eğlence sektörlerinin \%50 oranında yabancı kaynak kullandıklarını, restoran sektöründe ise varlıklarının dört katına yakın yabancı kaynak kullandıklarını saptamışlardır. Bu bağlamda Türk turizm sektörünün yabancı kaynak kullanım oranı bakımından Kim ve Ayoun (2005) çalışmasında yer alan turizm sektöründeki alt sektörlerden restoran alt sektörü dışında farklılık gösterdiğini söylemek mümkündür. Dolayısıyla Amerika turizm sektöründeki restoranlar hariç yabancı kaynak kullanımının Türk turizm alt sektörlerinden daha aşağıda olduğu önemli bulgular arasında yer almaktadır.

Tablo 4'de ise analize dâhil alt sektörlerin özsermaye/toplam kaynak oranları karşılaştırmalı olarak sunulmaktadır.

Tablo 4: Turizm Alt Sektörlerinin Özkaynak / Toplam Kaynak Oranları

\begin{tabular}{|l|l|l|l|l|}
\hline Özsermaye/Toplam Kaynak Oranı & $\mathbf{2 0 1 2}$ & $\mathbf{2 0 1 3}$ & $\mathbf{2 0 1 4}$ & Ort. \\
\hline Konaklama & 0,41 & 0,33 & 0,31 & 0,35 \\
\hline Yiyecek ve İçecek Hizmeti Faaliyetleri & 0,40 & 0,30 & 0,26 & 0,32 \\
\hline Seyahat Acentesi ve Tur Operatörlüğü Faaliyetleri & 0,18 & 0,15 & 0,14 & 0,16 \\
\hline Spor Faaliyetleri, Eğlence ve Dinlence Faaliyetleri & 0,35 & 0,30 & 0,25 & 0,30 \\
\hline
\end{tabular}

Özsermayenin toplam kaynak içerisindeki payını gösteren analiz sonuçları incelendiğinde alt sektörler bağlamında özsermayesi en güçlü olan alt sektörün konaklama sektörü buna karşın özsermayesi en zayıf olan sektörün ise seyahat acentesi ve tur operatörlüğü faaliyetleri alt sektörü olduğu görülmektedir. Yine incelenen yıllar itibariyle turizm alt sektörlerinin öz kaynaklarının azaldığı gözlenmektedir. Söz konusu durumun turizm sektöründe yabancı kaynaklara yönelmenin ve yıllar itibariyle oluşan zarar sebebiyle sermayenin erimesinden kaynaklandığı söylenebilir. Bu durumun sektörün finansal riskini ve iflas olasılıklarını arttırması bağlamında kritik öneme sahip olduğu ifade edilebilir.

Tablo 5'de analize dâhil alt sektörlerin yabancı kaynak/özsermaye oranları karşılaştırmalı olarak sunulmaktadır.

Tablo 5: Turizm Alt Sektörlerinin Yabancı Kaynak/Özsermaye Oranları

\begin{tabular}{|l|l|l|l|l|}
\hline Yabancı Kaynak/ÖzSermaye Oranı & $\mathbf{2 0 1 2}$ & $\mathbf{2 0 1 3}$ & $\mathbf{2 0 1 4}$ & Ort. \\
\hline Konaklama & 1,42 & $\mathbf{2 , 0 3}$ & 2,23 & 1,89 \\
\hline Yiyecek ve İçecek Hizmeti Faaliyetleri & 1,48 & 2,33 & 2,81 & 2,21 \\
\hline Seyahat Acentesi ve Tur Operatörlüğü Faaliyetleri & 4,57 & 5,54 & 5,93 & 5,35 \\
\hline Spor Faaliyetleri, Eğlence ve Dinlence Faaliyetleri & 1,83 & 2,29 & 3,05 & 2,39 \\
\hline
\end{tabular}

Yabancı kaynak kullanım oranını gösteren analiz sonuçları incelendiğinde turizm alt sektörlerinin öz kaynaklarının iki katından fazla yabancı kaynak yani borcunun olduğu görülmektedir. Söz konusu durum turizm sektörünün yüksek risk oranıyla faaliyette bulunduğunun bir göstergesidir. Seyahat acentesi ve tur operatörlüğü faaliyetleri alt sektörünün yabancı kaynak oranının öz kaynaklarının 5 katından fazla olması, bu sektörün en riskli alt sektörlerden biri olduğunu göstermektedir. Yüksek risk grubunda bulunan işletmelerin borçlanma maliyetlerinin zaman içerisinde artması ve faaliyet riskinin yüksek olduğu bu sektörde işletmelerin finansal sürdürülebilirliğini olumsuz etkileyen bir unsur olması dikkat çeken bir diğer önemli konu olarak karşımıza çıkmaktadır. 
Tablo 6'da analize dâhil alt sektörlerin kısa vadeli yabancı kaynak/toplam kaynak oranları karşılaştırmalı olarak sunulmaktadır.

Tablo 6: Turizm Alt Sektörlerinin Kısa Vadeli Yabancı Kaynaklar/ Toplam Kaynak Oranları

\begin{tabular}{|l|l|l|l|l|}
\hline KVYK/Toplam Kaynak & $\mathbf{2 0 1 2}$ & $\mathbf{2 0 1 3}$ & $\mathbf{2 0 1 4}$ & Ort. \\
\hline Konaklama & 0,25 & 0,25 & 0,23 & 0,24 \\
\hline Yiyecek ve Içecek Hizmeti Faaliyetleri & 0,38 & 0,40 & 0,43 & 0,40 \\
\hline Seyahat Acentesi ve Tur Operatörlüğü Faaliyetleri & 0,70 & 0,74 & 0,76 & 0,73 \\
\hline Spor Faaliyetleri, Eğlence ve Dinlence Faaliyetleri & 0,37 & 0,40 & 0,41 & 0,40 \\
\hline
\end{tabular}

Borçlanma oranlarından biri olan KVYK/ Toplam Kaynak oranı incelendiğinde yıllar itibariyle konaklama dışındaki alt sektörlerin kısa vadeli borç kullanımlarında bir yükseliş olduğu gözlenmektedir. Alt sektörlerin aktif yapıları incelendiğinde söz konusu sektörlerin toplam aktifleri içerisindeki dönen varlık oranları; Y\&i sektöründe \%43, seyahat sektöründe, konaklama ve spor faaliyetleri sektörlerinde ise $\% 25$ dolaylarında olduğu görülmektedir. Dolayısıyla konaklama alt sektörünün sabit sermaye ağırlıklı olduğu ve dönen varlıklarının kısa vadeli yabancı kaynaklarla finanse edildiği söylenebilir. Y\&l alt sektörünün dönen varlık ve duran varlık oranlarının birbirine yakın olduğu ve aynı zamanda kısa vadeli yabancı kaynaklarının \%40 civarında olduğu dikkate alındığında bu alt sektörde de dönen varlıkların kısa vadeli yabancı kaynaklarla finanse edilmesi açısından uyum içerisinde olduğu söylenebilir. Seyahat acentesi ve tur operatörlüğü faaliyetleri alt sektörüne bakıldığında ise bu sektörün dönen varlık ağırıklı olduğu gözlenmektedir. Yine bu sektörün kısa vadeli yabancı kaynaklarının \%78 civarında olması finansal açıdan uyumlu olduğunu göstermektedir. Spor, eğlence ve dinlence faaliyetleri alt sektöründe ise dönen varlıkların toplam varlıklar içerisindeki payı \%22 civarında olmasına rağmen kısa vadeli yabancı kaynakların toplam yabancı kaynaklar içerisindeki payı \%40 civarında gerçekleşmiştir. Buna göre bu sektörün dönen varlıklarına kıyasla daha fazla kısa vadeli borç kullandığı, net çalışma sermayesi açığı olduğu ve bu durumun finansal açıdan uyumlu olmadığı söylenebilir. Bu bağlamda spor, eğlence ve dinlence faaliyetleri alt sektörü dışında, diğer turizm alt sektörlerinin kısa vadeli borç kullanım oranlarının varlık yapılarıyla uyumlu olduğu söylenebilir.

Tablo 7'de analize dâhil turizm alt sektörlerinin uzun vadeli yabancı kaynak / toplam kaynak oranları karşılaştırmalı olarak sunulmaktadır.

\section{Tablo 7:Turizm Alt Sektörlerinin Uzun Vadeli Yabancı Kaynak/Toplam Kaynak Oranları}

\begin{tabular}{|l|l|l|l|l|}
\hline UVYK/Toplam Kaynak & $\mathbf{2 0 1 2}$ & $\mathbf{2 0 1 3}$ & $\mathbf{2 0 1 4}$ & Ort. \\
\hline Konaklama & 0,34 & 0,42 & 0,46 & 0,41 \\
\hline Yiyecek ve Içecek Hizmeti Faaliyetleri & 0,21 & 0,30 & 0,31 & 0,28 \\
\hline Seyahat Acentesi ve Tur Operatörlüğü Faaliyetleri & 0,12 & 0,11 & 0,10 & 0,11 \\
\hline Spor Faaliyetleri, Eğlence ve Dinlence Faaliyetleri & 0,27 & 0,30 & 0,34 & 0,30 \\
\hline
\end{tabular}

Kaldıraç oranlarından biri olan toplam kaynaklar içerisinde uzun vadeli yabancı kaynak kullanımı incelendiğinde seyahat acentesi ve tur operatörlüğü faaliyetleri alt sektörünün uzun vadeli yabancı kaynak tercihinin diğer alt sektörlere göre çok düşük seviyelerde gerçekleştiği gözlenmektedir. Söz konusu durum, varlık yapısı bağlamında incelendiğinde seyahat acentesi ve tur operatörlüğü faaliyetleri alt sektörünün dönen varlık ağırlıklı bir yapıda olmasından dolayı bu alt sektörün uzun vadeli borç kullanımını 
daha az tercih ettiği düşünülmektedir. Diğer yandan sabit sermaye yoğunluğu ortalama \%74 ile en yüksek alt sektörlerden biri olan konaklama alt sektörünün uzun vadeli borç kullanımının daha yüksek olduğu belirlenmiştir. Bu bağlamda konaklama ve seyahat acentesi ve tur operatörlüğü faaliyetleri alt sektörlerinin varlık ve kaynak yapısı arasında uyum olduğu söylenebilir. Yiyecek ve içecek hizmeti faaliyetleri alt sektörüne bakıldığında ise dönen varlık ve duran varlıkların birbirine yakın olduğu ve dönen varlıkların kısa vadeli yabancı kaynaklarla karşılandığı görülmektedir. Bu sektörün uzun vadeli yabancı kaynak oranının \%28 civarında gerçekleşmesi ise duran varlıkların bir kısmının uzun vadeli yabancı kaynaklarla diğer kısmının ise öz kaynaklarla finanse edildiğini göstermektedir. Böylece yiyecek ve içecek hizmeti faaliyetleri alt sektörünün de varlık ve kaynak yapısının uyumlu olduğu söylenebilir. Fakat spor faaliyetleri, eğlence ve dinlence faaliyetleri alt sektörünün duran varlık ağırlıklı olmasına karşın kısa vadeli yabancı kaynak tercihlerinin daha yüksek olduğu gözlenmektedir. Söz konusu durumun spor faaliyetleri, eğlence ve dinlence faaliyetleri alt sektöründeki işletmelerin varlık ve kaynak dengelerinin kurulamaması durumunda özellikle likidite sorunları yaşayabileceklerine işaret etmektedir.

Tablo 8'de analize dâhil turizm alt sektörlerinin ticari borç / kısa vadeli yabancı kaynak oranları karşılaştırmalı olarak sunulmaktadır.

\section{Tablo 8:Turizm Alt Sektörlerinin Ticari Borç/ Kısa Vadeli Yabancı Kaynaklar Oranları}

\begin{tabular}{|l|l|l|l|l|}
\hline Ticari Borç/KVYK & $\mathbf{2 0 1 2}$ & $\mathbf{2 0 1 3}$ & $\mathbf{2 0 1 4}$ & Ort. \\
\hline Konaklama & 0,20 & 0,23 & 0,24 & 0,23 \\
\hline Yiyecek ve İçecek Hizmeti Faaliyetleri & 0,56 & 0,56 & 0,49 & 0,54 \\
\hline Seyahat Acentesi ve Tur Operatörlüğü Faaliyetleri & 0,59 & 0,62 & 0,45 & 0,55 \\
\hline Spor Faaliyetleri, Eğlence ve Dinlence Faaliyetleri & 0,21 & 0,21 & 0,30 & 0,24 \\
\hline
\end{tabular}

Kısa vadeli yabancı kaynaklar içerisinde ticari borç oranını gösteren oran incelendiğinde Yiyecek ve İçecek Hizmeti Faaliyetleri (Y\&í) ve Seyahat Acentesi ve Tur Operatörlüğü vadede ağırlıklı olarak ticari borç kullandıkları gözlenmektedir. Söz konusu sonuç bu iki alt sektörün kısa vadeli banka kredisini tercih etmediklerini ve vadeli alımlar gerçekleştirdiklerini ve süreklilik gösterirse kısa vadede yüksek maliyetli borç kullandıklarını ifade etmektedir.

Tablo 9'da analize dâhil turizm alt sektörlerinin finansal borç/uzun vadeli yabancı kaynak oranları karşılaştırmalı olarak sunulmaktadır.

\section{Tablo 9:Turizm Alt Sektörlerinin Finansal Borç/Uzun Vadeli Yabancı Kaynaklar Oranları}

\begin{tabular}{|l|l|l|l|l|}
\hline Finansal Borç/UVYK & $\mathbf{2 0 1 2}$ & $\mathbf{2 0 1 3}$ & $\mathbf{2 0 1 4}$ & Ort. \\
\hline Konaklama & 0,88 & 0,90 & 0,92 & 0,90 \\
\hline Yiyecek ve İçecek Hizmeti Faaliyetleri & 0,85 & 0,91 & 0,86 & 0,87 \\
\hline Seyahat Acentesi ve Tur Operatörlüğü Faaliyetleri & 0,71 & 0,83 & 0,84 & 0,79 \\
\hline Spor Faaliyetleri, Eğlence ve Dinlence Faaliyetleri & 0,43 & 0,56 & 0,49 & 0,49 \\
\hline
\end{tabular}

Uzun vadeli yabancı kaynaklar içerisinde finansal borç kullanımını gösteren oran analizi sonuçlarına bakıldığında spor faaliyetleri, eğlence ve dinlence faaliyetleri alt sektöründe bu oranın $\% 50$ civarında, diğer alt sektörlerde ise $\% 80-\% 90$ civarında olduğu gözlenmektedir. Bu bağlamda turizm alanında faaliyet gösteren işletmelerin uzun vadeli borç tercihlerinin ağırlıklı olarak finansal borçlardan oluştuğu saptanmıştır. 
Tablo 10 'da analize dâhil turizm alt sektörlerinin finansal kiralama/uzun vadeli yabancı kaynak oranları karşılaştırmalı olarak sunulmaktadır.

\section{Tablo 10:Turizm Alt Sektörlerinin Finansal Kiralama/Uzun Vadeli Yabancı Kaynak} Oranları

\begin{tabular}{|l|l|l|l|l|}
\hline Finansal Kiralama/UVYK & $\mathbf{2 0 1 2}$ & $\mathbf{2 0 1 3}$ & $\mathbf{2 0 1 4}$ & Ort. \\
\hline Konaklama & 0,01 & 0,01 & 0,01 & 0,01 \\
\hline Yiyecek ve İçecek Hizmeti Faaliyetleri & 0,02 & 0,01 & 0,01 & 0,01 \\
\hline Seyahat Acentesi ve Tur Operatörlüğü Faaliyetleri & 0,02 & 0,00 & 0,02 & 0,02 \\
\hline Spor Faaliyetleri, Eğlence ve Dinlence Faaliyetleri & 0,04 & 0,05 & 0,17 & 0,09 \\
\hline
\end{tabular}

Sabit sermaye ağırlıklı işletmelerde maliyetleri düşürücü bir finansman kaynağı olan finansal kiralamanın uzun vadeli yabancı kaynaklar içindeki oranına bakıldığında finansal kiralamanın çok düşük düzeylerde kullanıldığı gözlenmektedir. Söz konusu sonuç Kahiloğulları ve Karadeniz (2015)'in halka açık konaklama şirketlerinin finansman yapılarını inceledikleri çalışmalarıyla paralellik göstermektedir. Bu bağlamda turizm işletmelerinin finansal kiralamayı hemen hemen hiç tercih etmedikleri ve bu kaynaktan faydalanmadıkları söylenebilir.

Tablo 11'de analize dâhil turizm alt sektörlerinin uzun vadeli yabancı kaynak yabancı kaynak oranları karşılaştırmalı olarak sunulmaktadır.

\section{Tablo 11:Turizm Alt Sektörlerinin Uzun Vadeli Yabancı Kaynak/Yabancı Kaynak Oranları}

\begin{tabular}{|l|l|l|l|l|}
\hline UVYK/Yabancı Kaynak & $\mathbf{2 0 1 2}$ & $\mathbf{2 0 1 3}$ & $\mathbf{2 0 1 4}$ & Ort. \\
\hline Konaklama & 0,58 & 0,63 & 0,67 & 0,63 \\
\hline Yiyecek ve İçecek Hizmeti Faaliyetleri & 0,36 & 0,43 & 0,42 & 0,40 \\
\hline Seyahat Acentesi ve Tur Operatörlüğü Faaliyetleri & 0,15 & 0,13 & 0,11 & 0,13 \\
\hline Spor Faaliyetleri, Eğlence ve Dinlence Faaliyetleri & 0,42 & 0,42 & 0,46 & 0,43 \\
\hline
\end{tabular}

Yabancı kaynaklar içerisinde uzun vadeli yabancı kaynak oranını gösteren analiz sonuçları incelendiğinde seyahat acentesi ve tur operatörlüğü faaliyetleri alt sektörünün \%13, diğer üç alt sektörün $\% 40$ 'ın üzerinde uzun vadeli yabancı kaynak kullandığı saptanmıştır. Buna göre konaklama alt sektörü dışındaki diğer alt sektörlerin yabancı kaynak kullanımının ağırlıklı olarak kısa vadeli olduğu gözlenmektedir. Konaklama ile birlikte yiyecek ve içecek hizmeti faaliyetleri alt sektörlerinin toplam yabancı kaynaklardaki uzun vadeli yabancı kaynak oranının \%40-\%60 arasında olmasının sabit varlık düzeyinin yüksek olmasından kaynaklandığı söylenebilir. Bu sonuç Karadeniz ve arkadaşlarının (2012) otel ve lokantalar sektörünün yabancı kaynakların vade yapısı açısından daha çok uzun vadeli yabancı kaynak kullandığı ve varlıkların finansmanında devamlı sermayeye ağırlık verdiğini saptadıkları çalışmanın sonuçlarıyla paralellik göstermektedir. Yine varlık yapısı bağlamında bakıldığında dönen varlık ağırlıklı olan seyahat acentesi ve tur operatörlüğü faaliyetleri alt sektörünün uzun vadeli yabancı kaynak kullanımının çok düşük olması kaynak varlık uyumunun bir göstergesi olarak değerlendirilebilir. Spor faaliyetleri, eğlence ve dinlence faaliyetleri alt sektörünün sabit sermaye ağırlıklı olmasına rağmen daha çok kısa vadeli yabancı kaynağı tercih etmesi bu alt sektörün uzun vadeli yabancı kaynak yaratmak konusunda sıkıntıları olduğunu göstermektedir.

Tablo 12'de analize dâhil turizm alt sektörlerinin kısa vadeli yabancı kaynak/ yabancı kaynak oranları karşılaştırmalı olarak sunulmaktadır. 
Tablo 12:Turizm Alt Sektörlerinin Kısa Vadeli Yabancı Kaynak/Yabancı Kaynak Oranları

\begin{tabular}{|l|l|l|l|l|}
\hline KVYK/Yabancı Kaynak & $\mathbf{2 0 1 2}$ & $\mathbf{2 0 1 3}$ & $\mathbf{2 0 1 4}$ & Ort. \\
\hline Konaklama & 0,42 & 0,37 & 0,33 & 0,37 \\
\hline Yiyecek ve Içecek Hizmeti Faaliyetleri & 0,64 & 0,57 & 0,58 & 0,60 \\
\hline Seyahat Acentesi ve Tur Operatörlüğü Faaliyetleri & 0,85 & 0,87 & 0,89 & 0,87 \\
\hline Spor Faaliyetleri, Eğlence ve Dinlence Faaliyetleri & 0,58 & 0,58 & 0,54 & 0,57 \\
\hline
\end{tabular}

Yabancı kaynaklar içerisinde kısa vadeli yabancı kaynakların kullanımını gösteren oran incelendiğinde analiz sürecinde alt sektörlerin genel olarak kısa vadeli borçlarında bir düşüş olduğu gözlenmektedir. Söz konusu düşüşün son yıllarda kredi bulmakta yaşanan sorunlardan kaynaklanmış olabileceği düşünülmektedir. Bunun yanı sıra dönen varlık oranları incelendiğinde söz konusu yıllarda dalgalanmaların aşağı yönlü olduğu gözlenmektedir. Bu bağlamda turizm alt sektörlerinde faaliyet gösteren işletmelerin varlık ve kaynak yapılarında uyuma dikkat ettiği söylenebilir.

Tablo 13'te analize dâhil turizm alt sektörlerinin kısa vadeli banka kredisi / kısa vadeli yabancı kaynak oranları karşılaştırmalı olarak sunulmaktadır.

\section{Tablo 13:Turizm Alt Sektörlerinin Kısa Vadeli Banka Kredisi/Kısa Vadeli Yabancı Kaynak Oranları}

\begin{tabular}{|l|l|l|l|l|}
\hline Kısa Vadeli Banka Kredisi/KVYK & $\mathbf{2 0 1 2}$ & $\mathbf{2 0 1 3}$ & $\mathbf{2 0 1 4}$ & Ort. \\
\hline Konaklama & 0,26 & 0,23 & 0,24 & 0,24 \\
\hline Yiyecek ve İçecek Hizmeti Faaliyetleri & 0,14 & 0,16 & 0,15 & 0,15 \\
\hline Seyahat Acentesi ve Tur Operatörlüğü Faaliyetleri & 0,19 & 0,21 & 0,28 & 0,22 \\
\hline Spor Faaliyetleri, Eğlence ve Dinlence Faaliyetleri & 0,15 & 0,15 & 0,23 & 0,18 \\
\hline
\end{tabular}

Turizm alt sektörlerinin kısa vadeli yabancı kaynaklar içerisinde banka kredisi kullanım oranlarına bakıldığında yıllar itibariyle artış veya azalışların olduğu görülmektedir. Turizm alt sektörleri arasında konaklama ve seyahat acentesi işletmelerinin kısa vadeli yabancı kaynaklar içerisinde banka kredilerini kullanım oranının daha yüksek olduğu gözlenmektedir. Turizm alt sektörlerinin kısa vadeli yabancı kaynaklar içerisinde banka kredisi kullanım oranının konaklama sektörü hariç ticari borç kullanım oranı altında olduğu gözlenmektedir. $\mathrm{Bu}$ bağlamda turizm işletmelerinin kısa vadeli banka kredisi yaratma konusunda sıkıntıları olduğu düşünülmektedir. Ayrıca borcun vergi kalkanı etkisinden faydalanamadıkları ve daha yüksek maliyetli kaynaklara yöneldikleri önemli bulgular arasındadır.

Tablo 14'te analize dâhil turizm alt sektörlerinin uzun vadeli banka kredisi / uzun vadeli yabancı kaynak oranları karşılaştırmalı olarak sunulmaktadır.

Tablo 14: Uzun Vadeli Banka Kredisi/Uzun Vadeli Yabancı Kaynak

\begin{tabular}{|l|l|l|l|l|}
\hline Uzun Vadeli Banka Kredisi/UVYK & $\mathbf{2 0 1 2}$ & $\mathbf{2 0 1 3}$ & $\mathbf{2 0 1 4}$ & Ort. \\
\hline Konaklama & 0,86 & $\mathbf{0 , 8 9}$ & 0,90 & 0,88 \\
\hline Yiyecek ve İçecek Hizmeti Faaliyetleri & 0,81 & 0,90 & 0,84 & 0,85 \\
\hline Seyahat Acentesi ve Tur Operatörlüğü Faaliyetleri & 0,66 & 0,81 & 0,82 & 0,76 \\
\hline Spor Faaliyetleri, Eğlence ve Dinlence Faaliyetleri & 0,39 & 0,51 & 0,35 & 0,42 \\
\hline
\end{tabular}


Turizm alt sektörlerinin uzun vadeli kaynak kullanımında banka kredisi oranını gösteren analiz sonuçları incelendiğinde finansal borç kullanım oranıyla aynı seviyede olduğu gözlenmektedir. Söz konusu oranların birbirine bu kadar yakın olması turizm sektöründe uzun vadeli yabancı kaynak yaratmak konusunda sıkıntılar olduğu bu sebeple banka kredilerinin tercih edildiği düşüncesini desteklemektedir. Son yıllarda devlet teşviklerinin azalması, sermaye piyasalarına açılma ve kaynak çeşitliliğinin olmamasının işletmelerin banka kredilerine yönelmelerinin sebepleri arasında olduğu düşünülmektedir.

\section{Sonuç}

Son yıllarda yaşanan finansal krizlerle birlikte yoğun rekabet ortamında işletmelerin faaliyetlerini sağlıklı bir şekilde devam ettirmeleri ve finansal güçlerini koruyabilmeleri açısından finansman kararları önem taşımaktadır. Turizm işletmeleri, değişken talep düzeyi, yüksek politik ve ekonomik risk ortamının yanı sıra sabit ve değişken maliyetlerin yüksek, bununla birlikte işletme sermayesi intiyacının da yüksek tutarlarda gerçekleştiği, düşük kar marjı ve yüksek döviz kuru riskinin olduğu bir sektörde faaliyet göstermektedir. Dolayısıyla turizm işletmeleri, kaynak ve varlık yapılarını dengeleyememelerinin yanı sıra sistematik ve sistematik olmayan risk unsurlarından etkilenmeleri sebebiyle kısa ve uzun vadede vadesi gelen borçlarının ödenmesi konusunda finansal sorunlarla karşı karşıya kalabilmektedir.

Bu çalışmada TCMB'nin hazırladığı konaklama, yiyecek ve içecek hizmeti faaliyetleri, seyahat acentesi ve tur operatörlüğü faaliyetleri, spor faaliyetleri, eğlence ve dinlence faaliyetleri alt sektörlerinin 2012, 2013 ve 2014 yıllarına ait sektör bilançoları üzerinde bu sektörlerin varlık ve kaynak yapısı incelenmiş, finansman tercihleri oran analizi yöntemiyle karşılaştırmalı olarak ortaya konmuştur. Konaklama sektöründe 421 , yiyecek ve içecek hizmeti faaliyetleri sektöründe 72 , seyahat acentesi ve tur operatörlüğü faaliyetleri sektöründe 52, son olarak spor faaliyetleri, eğlence ve dinlence faaliyetleri sektöründe 17 işletmenin konsolide edilmiş finansal bilançoları bulunmaktadır. Çalışmada turizm alt sektörlerinin finansal kaynak yapısının kompozisyonu, finansman kaynaklarının türleri, vadeleri ve yıllar içerisindeki değişimleri finansal yapı oranları kullanılarak ortaya konulmaya çalışılmıştır.

Yapılan analizler sonucunda seyahat acentesi ve tur operatörlüğü faaliyetleri alt sektörünün dönen varlık ağırlıkı, yiyecek ve içecek hizmeti faaliyetleri sektöründe dönen ve duran varlıklarının birbirine yakın olsa da duran varlıkların daha yüksek olduğu, konaklama ile spor faaliyetleri, eğlence ve dinlence faaliyetleri alt sektörlerinin ise duran varlık ağırlıklı olduğu belirlenmiştir. Bu bağlamda kaynak yapıları incelendiğinde seyahat acentesi ve tur operatörlüğü faaliyetleri alt sektörünün kaynaklarının \%80'ini yabancı kaynakların oluşturduğu ve yabancı kaynakların \%85'ini ise kısa vadeli yabancı kaynakların oluşturduğu ortaya çıkmaktadır. Bu sektörün dönen varlık ağırlıklı olması ve bu varlıkların büyük kısmının kısa vadeli ticari borç ve banka kredileri ile finanse edildiği göz önüne alındığında yüksek riskli bir sektör olduğu söylenebilir. Spor faaliyetleri, eğlence ve dinlence faaliyetleri alt sektörünün duran varlık ağırlıkı olmasına karşın kısa vadeli finansman kaynağı olan ticari borçlara yöneldiği belirlenmiştir. Buna göre bu sektörün varlık yapısına uygun bir kaynak yapısının olmadığı ve uzun vadede finansal sıkıntıyla karşı karşıya kalabileceği düşünülmektedir. Konaklama, yiyecek ve içecek hizmeti faaliyetleri alt sektörlerine bakıldığında ise varlık yapısıyla uyumlu olarak kaynak kullanımına gidildiği ve sabit sermaye ağırlıklı olan bu sektörlerin kaynaklarında daha çok uzun vadeli yabancı kaynakları kullandıkları ortaya çıkmıştır. Ancak, bu sektörlerin uzun vadeli yabancı kaynaklarının tamamına yakın bir kısmının banka kredilerinden oluşması, kaynak 
çeşitliliği yaratmak konusunda sorunlarının olduğuna işaret etmektedir. Düşük maliyetli bir kaynak olarak varsayılan finansal kiralamanın turizm sektörünü oluşturan işletmelerde kullanılmaması dikkat çeken önemli sonuçlar arasındadır.

Turizm alt sektörlerinde yabancı kaynak oranının öz kaynaklarının iki katından fazla olduğu analiz sonucunda elde edilen diğer önemli bulgular arasındadır. Ayrıca yabancı kaynak oranının yüksek olması finansal riski artıran bir unsur olması bağlamında dikkat edilmesi gereken bir husus olarak karşımıza çıkmaktadır.

Konuyla ilgili literatür incelendiğinde Türkiye'de turizm sektörünü oluşturan alt sektörlerin finansman yapısını karşılaştırmalı olarak inceleyen bir çalışmaya tarafımızca rastlanmamıştır. Bu kapsamda çalışmanın literatüre sağlayacağı katkı ve turizm sektörünün finansman yapısını ortaya koyması ve eksiklerini tespit etmesi bağlamında önem arz ettiği düşünülmektedir. Çalışma sonucunda elde edilen bulguların Kim ve Ayoun (2005)'un çalışmalarında borç kullanım oranı bakımından farklılık gösterdiği, Kahiloğulları ve Karadeniz (2015)'in çalışmasında halka açık turizm şirketlerinin finansman yapısı ve tercihleriyle paralellik gösterdiği belirlenmiştir. Ayrıca Karadeniz ve arkadaşlarının (2012), otel ve lokantalar sektörünün yabancı kaynakların vade yapısı açısından daha çok uzun vadeli yabancı kaynak kullandığı ve varlıkların finansmanında devamlı sermayeye ağırlık verdiğini saptadıkları çalışmanın sonuçlarıyla paralellik göstermektedir. Çalışma sonucunda elde edilen bulgular neticesinde turizm alt sektörlerinde faaliyet gösteren işletmelerin finansal kaynak çeşitliliğini arttırma, risklerden korunma ve maliyetleri azaltma yönünde girişimlerde bulunmaları önerilmektedir. Kaynak çeşitlendirmesi bağlamında sermaye piyasalarına açılma, swap, future, forward gibi hedge işlemlerini kullanarak faiz ve döviz kuru risklerinden korunma, finansal kiralamaya yer vererek maliyetleri azaltma gibi seçenekler tercih edilebilir. Çalışma sınırlı bir süreyi ve gönüllülük esasına dayalı olarak finansal tablolarını TCMB ile paylaşan işletmelerin oluşturduğu alt sektörleri kapsamaktadır. İleride yapılacak çalışmalar daha uzun süre ve farklı sektörleri kapsayacak şekilde gerçekleştirilebilir. Bununla birlikte farklı finansal analiz tekniklerinin kullanılması ile gerçekleştirilecek çalışmalar daha geniş bir karşılaştırmaya imkân tanıyabilir.

\section{Kaynakça}

Andrew, P. ve Schmidgall, R. (1993), Financial Management For The Hospitality Industry, USA: AH\&MA.

Antzoulatos, A. A., Apergis, N. ve Tsoumas, C. (2011), "Financial Structure and Industrial Structure", Bulletin of Economic Research, ss.109-139.

Arslan, O. (2005), "A Study on the CapitalStructure of the Turkish Real Sector Firms", İstanbul Üniversitesi Siyasal Bilgiler Fakültesi Dergisi, 33, ss. 103-118.

Bichon, P. (2009). Europe: Refinancing A Hotel in Today's Restricted Debt Markets [elektronik versiyon]. HVS Library: http://www.hvs.com/article/4307/europerefinancing-a-hotel-in-todays-restricted-debt/. (28.11.2014).

Brealey, R. A., Myers, S. C. ve Marcus , A. J. (2001), Fundamentals of Corporate Finance, Boston: The McGraw-Hill Companies, Inc.

Ceylan, A. ve Korkmaz, T. (2008), İşletmelerde Finansal Yönetim, Bursa: Ekin Basım Yayın Dağıtım.

Civan, M. ve Cenger, H. (2013). Borsada İşlem Gören Turizm İşletmelerinin Finansal Yapı ve Karlılık Oranları Arasındaki İlişkinin Analizi. 17. Finans Sempozyumu. Muğla: Muğla Üniversitesi, ss. 354-363.

Değirmen, S. ve Gündoğdu, Y. (2010), “Türkiye'de İhracat Yapan Firmaların Finansman Stratejileri”, Business and Economics Research Journal, 4(1), ss. 1-18. 
Fritsch, C. H. ve Ivy, L. (2014). The New Reality of Hotel Financing [elektronik versiyon]. Hotel Brokers International: http://hbihotels.com/user_storage/New\%20Reality\%20of\%20Hotel\%20Financing .pdf. (03.01.2016)

Gençtürk, M., Dalğar, H. ve Yılmaz, T. (2011),"Finansal Krizlerin İşletmelerin Finansman Kararlarına Etkileri: IMKB'de İşlem Gören İşletmeler Üzerinde Bir Araştırma", C.Ü. Iktisadi ve Idari Bilimler Dergisi, 12 (1), ss. 187-207.

Gökçe, D. (2015). "Hürriyet Ekonomi Haberleri".http://www.hurriyet.com.tr/silkar-turizmiflas-erteleme-istedi-26595353. (05.03.2016).

Jagels, M. G. ve Coltman, M. (2004), Hospitality Management Accounting,New Jersey: John Wiley\&Sons, Inc.

Kahiloğulları, S. Ve Karadeniz, E. (2015), "Halka Açık Konaklama Şirketlerinin Finansal Yapılarının Analizi: Uluslar arası Bir Karşılaştırma”, Çankırı Karatekin Üniversitesi IiBF Dergisi, 5,ss. 531-548.

Karadeniz, E., İskenderoğlu, Ö., Kandır, S. Y. ve Önal, Y. B. (2012),"Türkiye Cumhuriyet Merkez Bankası Sektör Bilançoları Yardımıyla Oteller ve Lokantalar Sektörünün Finansman Kararlarının İncelenmesi”, Seyahat ve Otel Iş̧letmeciliği Dergisi, 8 (1), ss. 17-28.

Kim, W. G. veAyoun, B. (2005), "Ratio Analysis For The Hospitality Industry: A Cross Sector Comparison Of Financial Trends In The Lodging, Restaurant, Airline, And Amusement Sectors", The Journal of Hospitality Financial Management, 13(1), ss. 59-78.

Küçükaltan, K. D. ve Açıkgöz, A. F. (2011),Uluslararası Otel İşletmelerinin Finansmanı. Tekirdağ, Değirmenaltı, Trakya.

Küçükaltan, K. ve Eskin, İ. (2008), “Türkiye'deki Otel İşletmelerine Bir Finansman Modeli Olarak Teşvikler", Trakya Üniversitesi Sosyal Bilimler Dergisi, 10(2), ss. 158-172.

Küçüközmen, C. C. ve Oğuz, D. (2008),BASEL Il'ye Geçiş Sürecinde KOBi'lerin Finansman Sorunları: Konya Ili Örneği. BASEL II'ye Geçiş Sürecinde Kobilerde Genel Durum Değerlendirmesi: Sorunlar ve Çözüm Önerileri (s. 41-57). İzmir: İzmir Ekonomi Üniversitesi Yayınları.

Korkmaz, T. Ve Ceylan, A. (2010), Sermaye Piyasası ve Menkul DeğerAnalizi, Bursa: Ekin BasımYayın Dağıtım.

Langemeier, M. R. (2004), Financial Ratios Used in Financial Management, USA: Kansas StateUniversity.

Önal, Y. B., Karadeniz, E. ve Koşan , L. (2006),“Finansal Analiz Tekniklerinin Otel İşletmelerinde Stratejik Yönetim Aracı Olarak Kullanımına İlişkin Teorik Bir Değerlendirme", Seyahat ve Otel Işletmeciliği Dergisi, 3(2), ss. 16-25.

Rioja, F. ve Valev, N. (2012), "Financial Structure and Capital Investment”, Applied Economics, ss.1783-1793.

Salameh, H. M., Al-Zubi, K. A., ve Al-Zıbi, B. (2012), "Capital Structure Determinants and Financial Performance Analytical Study in Saudi Arabia Market 2004-2009", International Journal of Economic Perspectives, 6(4),ss. 18-33.

Sayılgan, G. ve Uysal, B. (2011), "Türkiye Cumhuriyet Merkez Bankası Sektörel Bilançoları Kullanılarak Sermaye Yapısını Belirleyen Faktörler Üzerine Bir Analiz: 1996-2008", Ankara Üniversitesi SBF Dergisi, 66(4), ss.101-124.

Serrasqueiro, Z. ve Nunes, P. M. (2014),"Financing Behaviour of Portuguese SMEs in Hotel Industry", International Journal of Hospitality Management, 43,ss. 98-107.

Swain, R. N. ve Patnaik, B. (2013),"Financial Structure Analysis Of Indian Companies: A Review Of Literature", Asia Pacific Journal Of ResearchIn Business Management, 4(1/2), ss. 87-94.

White, I. G.,Sondhi , C. A. ve Fried, D. (1997), The Analysis and Use Of Financial Statements. New York: John Wiley \& Sons Inc. 